\title{
A Study on the Relationship between Resilience and Turnover Intention: With an Emphasis on the Mediating Roles of Job Satisfaction and Job Stress
}

\author{
Parastoo GHANDI ${ }^{1}$, Elahe HEJAZI ${ }^{3}$, Nahid GHANDI ${ }^{2}$ \\ ${ }^{1}$ Master of Educational Psychology, University of Tehran \\ ${ }^{2}$ Elahe Hejazi, Associate Professor at University of Tehran \\ ${ }^{3}$ Master of Educational Psychology, Islamic Azad University, Science and Research Branch, Tehran
}

\begin{abstract}
:
This study attempted to investigate the relationship between resilience, job satisfaction, job stress and turnover intention among counselors through path analysis. For this purpose, 207 counselors at Shahriar-based schools were randomly selected as sample. Then, the subjects filled several questionnaires including Connor and Davidson Resiliency Scale (2003); Job Satisfaction by Rutherford et al. (2009); Job Stress by Stanimter (1997) and Turnover Intention by Babakas et al. (2009). The findings obtained through path analysis showed that resilience had a positive, significant and direct effect on job satisfaction, while the direct effect of resilience on job stress was negative and significant. Moreover, job satisfaction had a significantly negative effect on turnover, while job stress had a significant direct effect on turnover intention. The effect of job stress on job satisfaction was negative and significant. The results showed that the relationship between resiliency and turnover was mediated by job satisfaction and job stress.
\end{abstract}

Keywords: resilience, job stress, job satisfaction, turnover intention

\section{Introduction}

As a technical term in the management literature, turnover refers to an individual's voluntary departure(resignation, redemption, early retirement and transfers to other organizations) from an organization. In many cases, such decisions may impose irreversible costs on organizations (Allen and Bryant Allen and Bryant, 2012).Broadly defined, turnover represents a departure from an organization and expression of dissatisfaction with the job. More specifically, it can be defined as an individual's shift in organizational membership, covering a wide range of reappointments and substitutions (Rondeau and Wagar 2016).When a person gives up working or leaves the membership in an organization, it involves turnover (Bougheas, Davidson, Upward and Wright, 2015).One of the behavioral researchers (Price, 1977; quoted by Lee, Lee and Bernstein, 2013) put an emphasis on the particular definition of turnover, concluding in a series of studies that quitting jobs can be divided into two main categories: voluntary/optional or involuntary/mandatory. They stressed that the categories need to be distinguished, since there is a huge difference between an individual who leaves an organizational on a personal decision and an individual whose position is canceled by the organizational 
owners or managers. At the organizational level, there is plenty of evidence that upper turnover gives rise to recruitment and replacement costs (Dairy and Iversen, 1996, Manley, 1996; quoted by Rebollo- Sanz, 2012). Additional consequences of turnover are training and socialization of new individuals, lower production, organizational performance and efficiency until the newcomers gain skills and experience in their respective fields. In addition, issues such as coordination between new employees with their peers and immediate supervisors, new individual compliance with the relevant working groups and organizational teams can also negatively affect the morale of other employees. If the rate of turnover soars in the organization, there would be discredit (Ahn, 2015). In fact, Hom and Griffeth (1995) stated that voluntary turnover of members of an organization can reduce effectiveness. Accordingly, it is critical to study turnover intention. Moreover, the costs of turnover can be curtailed by finding out whether an employee is in a state of turnover, thus enabling organizations to take measures to sustain employees (Handlon, 2009). In this light, the present study intended to explore the role of resilience, job stress and job satisfaction in predicting the turnover intention among counselors.

In this regard, job satisfaction is variable repeatedly explored in organizational behavior studies. The traditional model of job satisfaction emphasizes on all of emotions that a person has about their job. Whether or not an individual is satisfied with a particular job depends on the nature of the job and individual expectations of the job. Hence, job satisfaction refers to emotional orientation of employees towards their jobs ( $\mathrm{Lu}$ et al., 2012). Job satisfaction can be associated with performance in organizational environments. Research results (Hudgins, 2016) showed a perfect correlation between job dissatisfaction and turnover. The results obtained by Huang et al. (2016) showed that employees' perceptions of safe work environment had a significant relationship with occupational involvement and turnover intention. Furthermore, the results of this study indicated that job satisfaction mediated in relationship between safe work environment and turnover intention. Additionally, Kuo, Lin and Li (2014) showed that job satisfaction mediated the relationship between job stress and turnover intention.

On the other hand, job stress can be regarded as a set of stressful factors and job-related conditions that most people agree about their stressor nature. For example, one of the stressful conditions associated with job occurs when a worker or employee is subject to excessive pressure or desire in the work environment, while having limited time to achieve that desire. Naturally, the individuals face criticisms from their superiors when then fail to carry out their tasks (Zabetian, 2011). In the definition of occupational stress, Randall (2006) refers to the terms as interaction between working conditions and individual characteristics, so that the demands of the workplace and therefore the associated pressures are greater than the individual scope of capabilities. In general, job stress is a type of stress associated with working environment or factors related with an individual's working environment. Change in work activities such as new technology or goals may cause stress (Park et al., 2009).

According to the results by Guchait, Paşamehmetoğlu and Madera (2016), greater job stress leads to higher job turnover among employees. The results obtained by Yang, Ju and Lee (2016) in relation to the effects of job stress on self-esteem, job satisfaction and 
turnover intention showed that job stress had a significant negative correlation with job satisfaction. Moreover, occupational stress has a significant and positive relationship with turnover intention.

On the other hand, the concept of resiliency has become increasingly important over the last two decades (Cicchetti and Garmezy, 1993; quoted by Charney, 2014).Originating from natural sciences into psychology literature, this concept has been defined in different ways (Tsouloupos, Carson, Matthews, Grawitch, Barber, 2010). Resilience is the ability to withstand tragedies and overcome problematic situations in life (Marsh, 1996; quoted by Hetherington and Blechman, 2014); the process of compliance with unfavorable conditions (Newman, 2003; quoted by Huling and Gunderson, 2016) and a dynamic process that reduces the negative consequences of endangered and threatened situations (Fergus and Zimmerman, 2005).Connor and Davidson (2003) argued that resiliency is the individual's ability to maintain the bio-psychological balance under dangerous situations. Resilience also involves a return to the initial balance or equilibrium level (in threatening situations), thus providing successful adaptability in life (Kumpfer, 2002). In fact, resiliency is now regarded as active and productive participation of individuals in their environments. In addition, a recovery with positive outcomes emotional resiliency, emotional and cognitive (Garmzi, 1991; Rutter, 1999; Lotter, Cicchetti, Becker, 2000; Masten, 2001). Rutter (2012) deemed resilience an ability to cope with stress and depression, according to which coping can help individuals return to normal performance. According to the results by Hudgins (2016), high resiliency is associated with higher job satisfaction among employees, while resiliency is negatively associated with turnover intention.

Given the above mentioned facts, there were no studies in the relevant literature on the simultaneous roles of resiliency, job satisfaction and job stress in turnover intention among counselors. For that purpose, this study responded to the lack of a model for predicting turnover intention among counselors according to three variables of resiliency, job satisfaction and job stress. As seen in Figure (1), resiliency is an independent variable, job satisfaction and job stress are mediators and turnover is the dependent variable.

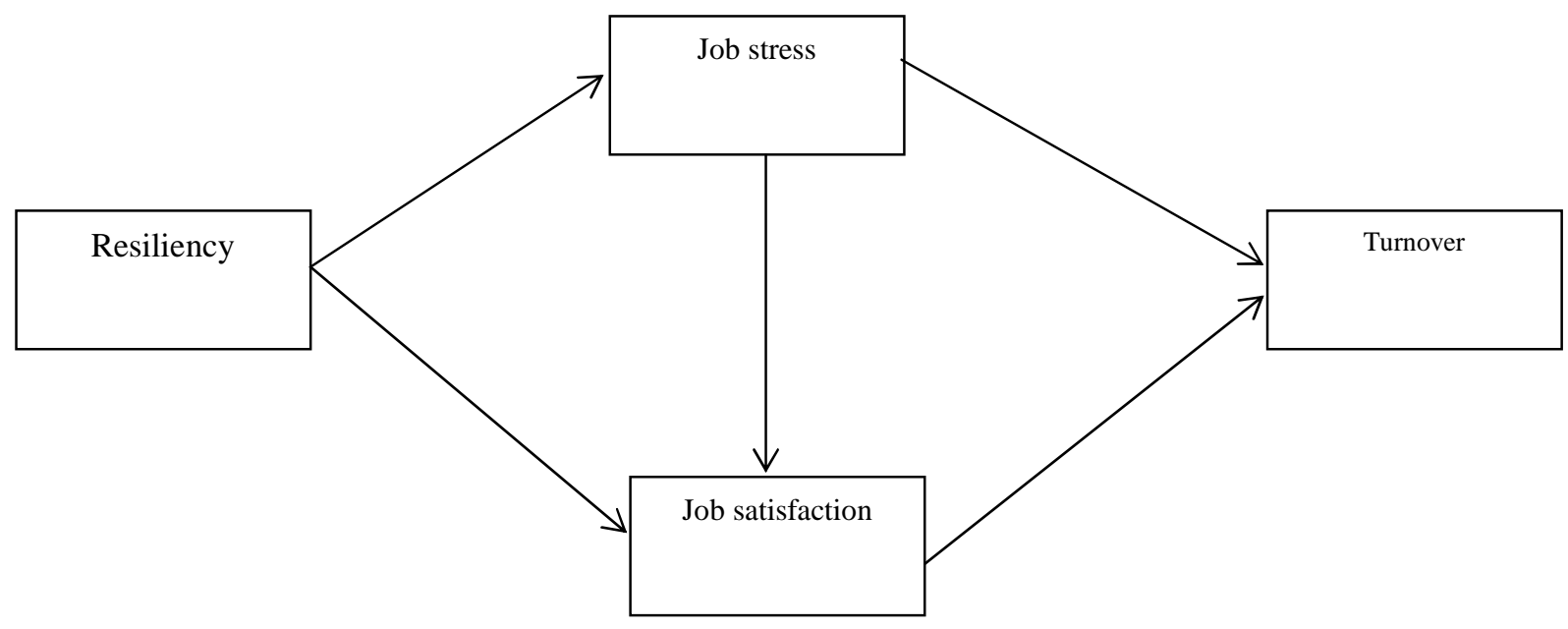

Figure 1: Conceptual model

According to the conceptual model shown in Figure (1), the research hypotheses are: 
1. Resiliency has a direct effect on job satisfaction.

2. Resiliency has a direct effect on job stress.

3. Job satisfaction has a direct effect on turnover.

4. Job stress has a direct effect on turnover.

5. Job stress has a direct effect on job satisfaction.

6. job satisfaction and job stress mediate the relationship between resiliency and turnover.

\section{Methodology}

This was a descriptive (non-experimental), correlational study carried out by path analysis, where the relationships between variables were explored under a causal model.

2.1.

Statistical population and sample

The statistical population comprised a total of school counsellors, of which 230 were randomly selected as sample and then given questionnaires to fill out. Of the questionnaires distributed, 213 were returned, but 6 questionnaires were eliminated because of incomplete responses. Finally, 207 questionnaires were analyzed.

2.2.

Data collection tools

This study involved questionnaires on resilience, job satisfaction, job stress and turnover intention to measure the variables. The validity and reliability of variables were examined through confirmatory analysis and Cronbach's alpha. The confirmatory factor is a theoretical testing model, in which researchers initiate their analyses with a previous hypothesis. Based on a strong theoretical and empirical foundation, this model specifies which variables are correlated with which factors, and which factors are correlated with which factors. The construct validity was evaluated through a reliable method by which the researchers can test the hypotheses about the factor structure of data in a pre-set model against a number and specific composition of factors. The confirmation method tests the optimum consistency of factor constructs observed and in theory for datasets after identifying the pre-experimental factors through determining the predetermined factor model fit.In this study, the confirmatory factor analysis model was evaluated through df/c2, RMSEA, GFI and AGFI. In this regard, df/c2 has no fixed criteria for an acceptable model, but a small value of df/c2 indicates a better fit of the model (Hooman, 2008).

Brownie and Kadeck advised to use Root Mean Square Error of Approximation (RMSEA) which was proposed by Steger (1990) as the size difference for each degree of freedom. RMSEA is equal to or less than 0.05 for good models. Higher values up to 0.08 represent a reasonable approximation error in the population.Models with RMSEA of 0.10 or more are poorly fit. Jarzcag and Sorium (1989) introduced GFI and AGF in LISREL. They demonstrate the extent to which a model fits. Conventionally, the values of GFI and AGFI should be equal to or greater than 0.90 before the model is accepted (Hooman, 2008).

Resilience: The Connor-Davidson Resilience Scale (2003) was employed to measure resiliency. The questionnaire covers various aspects of resiliency including a sense of personal empowerment, confidence in individual instincts, sense of support and social security, spiritual faith, positive acceptance of change, resistance to negative effects and 
pragmatic approach to problem-solving. This scale consists of 25 items formulated based on a five-point Likert scale ranging from Never "1" to Always "5". In the present study, the internal consistency was calculated by Cronbach's alpha to be 0.94 . Moreover, the indices obtained from confirmatory factor analysis $\mathrm{GFI}=0.94$, RMSEA=0.061 and AGFI $=0.91$ shows the model fit to data.

Job satisfaction: This variable was measured by Rutherford et al. questionnaire (2009).This scale consists of 4 items formulated based on a five-point Likert scale ranging from completely disagree " $1 "$ to completely agree "5". In the present study, the internal consistency was calculated by Cronbach's alpha to be 0.88 . Moreover, the indices obtained from confirmatory factor analysis GFI=0.97, RMSEA=0.027 and AGFI=0.95 shows the model fit to data.

Job stress: This variable was measured by Stanimter stress questionnaire (1977). The questionnaire consists of 36 items about stressful situations in work environment dealing with stress related to work environment, co-workers and supervisors. The items have been formulated on a 3-point scale ranging from not true "0" somewhat true " 1 " and absolutely true "2". The minimum and maximum scores in the questionnaire are 0 and 72, respectively. In the present study, the internal consistency was calculated by Cronbach's alpha to be 0.95 . Moreover, the indices obtained from confirmatory factor analysis GFI=0.94, RMSEA=0.069 and AGFI=0.90 shows the model fit to data.

Turnover intention: In order to measure the turnover intention, Babakas et al' scale (2009) was used on a general level of turnover intention: This questionnaire has 4 items, scored based on a 5-point Likert ranging from strongly disagree (1) to strongly agree (5). In the present study, the internal consistency was calculated by Cronbach's alpha to be 0.87. Moreover, the indices obtained from confirmatory factor analysis GFI $=0.95$, RMSEA $=0.031$ and AGFI=0.94 shows the model fit to data.

\section{3.}

\section{Data analysis method}

After calculation of the descriptive variables, the causal relationships between variables were examined through path analysis. Path analysis was first developed by Sewall Wright (1934), applied as multivariate regression in relation to the formulation of a causal models. Its purpose is to provide quantitative estimates of causal relationships between a set of variables (Hooman, 2008). The model presented in this research consists of resiliency as an independent variable, job satisfaction and job stress as mediators and turnover as the dependent variable. SPSS and LISREL were used to analyze the data.

\section{Findings}

Given that the analysis of causal patterns is based on correlation matrix, the correlation matrix, mean and standard deviation of variables are presented in Table (1). 
Bulletin de la Société Royale des Sciences de Liège, Vol. 86, special issue, 2017, p. 189 - 200

Table 1: Correlation matrix of variables

\begin{tabular}{|c|c|c|c|c|}
\hline Variables & Resilience & $\begin{array}{c}\text { Job } \\
\text { satisfaction }\end{array}$ & Job stress & $\begin{array}{c}\text { Turnover } \\
\text { intention: }\end{array}$ \\
\hline Resiliency & 1 & & & \\
\hline Job satisfaction & ${ }^{* *} 0.56$ & 1 & 1 & \\
\hline Job stress & ${ }^{* *} 0.48-$ & ${ }^{* *} 0.54-$ & ${ }^{*}$ & 0.50 \\
\hline Turnover intention: & ${ }^{* *} 0.51-$ & ${ }^{* *} 0.53-$ & 0.48 & 3.12 \\
\hline Mean & 3.01 & 2.99 & 0.43 & 0.97 \\
\hline Standard deviation & 0.70 & 1.02 & & \\
\hline
\end{tabular}

As seen in Table (1), the correlation between resiliency and job satisfaction $(r=0.56)$ is positive and significant. However, the correlation between resiliency and job stress $(r=-$ $0.48)$ and turnover intention $(\mathrm{r}=-0.51)$ is negative and significant at $(\mathrm{P}<0.01)$ The correlation between job satisfaction and job stress $(\mathrm{r}=-0.54)$ and turnover intention $(\mathrm{r}=-$ $0.53)$ is negative and significant at $(\mathrm{P}<0.01)$ The correlation between job stress and turnover intention $(\mathrm{r}=0.50)$ is positive and significant.

Figure (2)illustrates the tested model. The numbers on the paths are standard parameters. As can be seen, resilience has a positive and significant effect on job satisfaction, but its effect on job stress is negative and significant. Job stress has a significant and negative effect on job satisfaction, but a positive and significant effect on turnover intention. Job satisfaction has a significant negative effect on turnover intention.

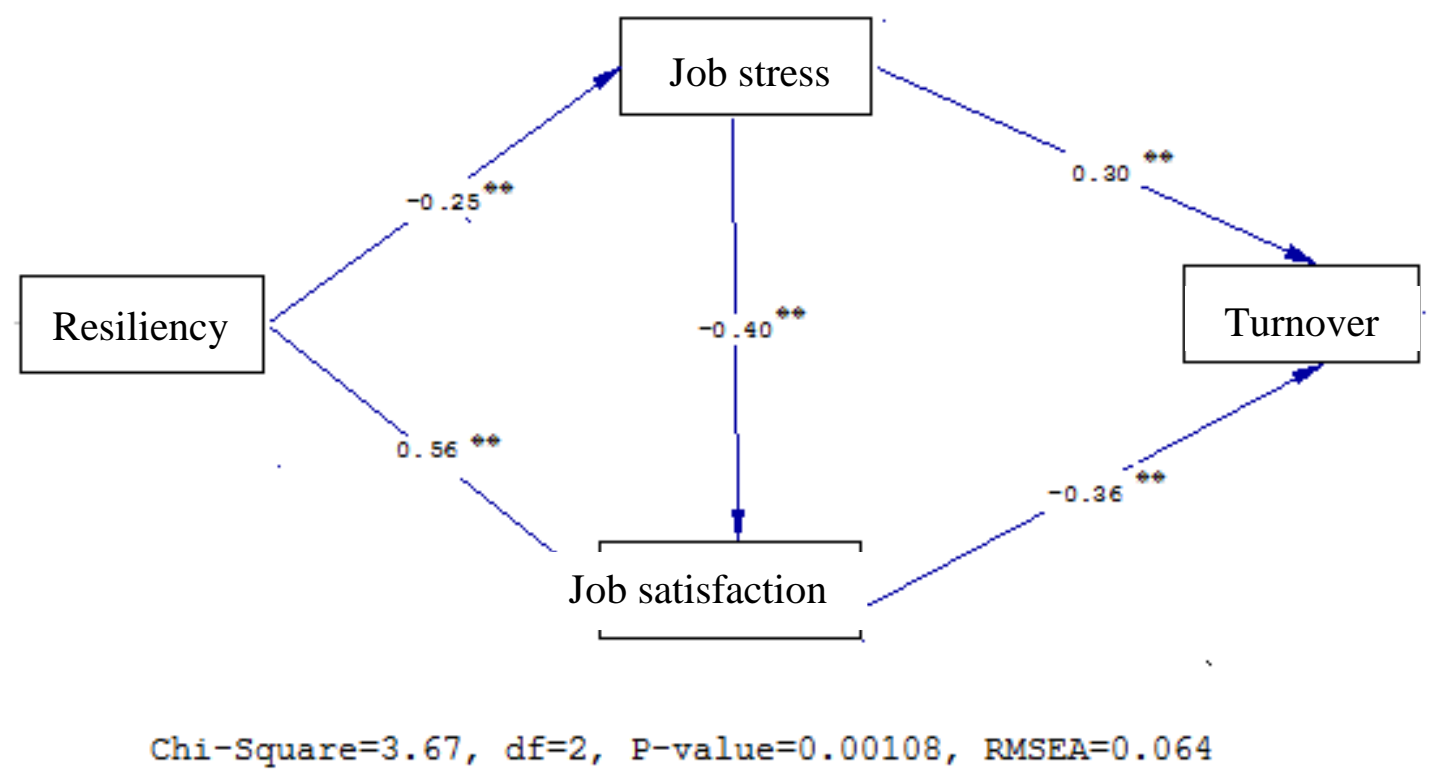

Figure 2: fitted model for predicting turnover intention among school counselors

Since the aim of this study was to examine the mediating role of job satisfaction and job stress in resiliency and turnover intention through path analysis, Table (2) displays the direct and indirect effects, and total effects, explained variance and significance levels of variables. 
Bulletin de la Société Royale des Sciences de Liège, Vol. 86, special issue, 2017, p. 189 - 200

Table 2: Estimation of standardized coefficients, direct and indirect effects, total effect and explained variance of the model

\begin{tabular}{|c|c|c|c|c|}
\hline Path & Direct effect & Indirect effect & Total effect & $\begin{array}{c}\text { Explained } \\
\text { variance }\end{array}$ \\
\hline $\begin{array}{c}\text { On turnover intention from: } \\
\text { Resiliency } \\
\text { Job satisfaction } \\
\text { Job stress }\end{array}$ & $\begin{array}{c}(5.41-)^{* *} 0.36- \\
(4.49)^{* *} 0.30\end{array}$ & $\begin{array}{c}(6.21-)^{* *} 0.34- \\
- \\
(3.78)^{* *} 0.14\end{array}$ & $\begin{array}{l}{ }^{* *} 0.34- \\
{ }^{* *} 0.36- \\
{ }^{* *} 0.44\end{array}$ & $36 \%$ \\
\hline $\begin{array}{c}\text { On job satisfaction from: } \\
\text { Resiliency } \\
\text { Job stress }\end{array}$ & $\begin{array}{l}(9.62)^{* *} 0.56 \\
(5.81-)^{* *} 0.40-\end{array}$ & $\begin{array}{c}(2.97-)^{* *} 0.10 \\
-\end{array}$ & $\begin{array}{l}{ }^{* *} 0.66 \\
{ }^{* *} 0.40-\end{array}$ & $47 \%$ \\
\hline $\begin{array}{c}\text { On job stress from: } \\
\text { Resilience }\end{array}$ & $(3.70-)^{* *} 0.25-$ & - & ${ }^{* *} 0.25$ & $6 \%$ \\
\hline
\end{tabular}

$$
0.05^{*} \mathrm{P}<0.01>^{* *} \mathrm{P}
$$

As seen in Table (2), the direct effect of resiliency on job satisfaction $(\beta=0.56)$ is significant and positive, while its effect on job stress $(\beta=-0.25)$ is negative and significant. Job stress has a direct effect on job satisfaction $(\beta=-0.40)$ which is negative and significant. The direct effect of job satisfaction on turnover intention $(\beta=-0.36)$ is negative and significant. Resilience has an indirect effect on job satisfaction $(\beta=0.10)$ which is significant and positive, whereas its indirect effect on turnover intention $(\beta=-0.34)$ is negative and significant. The indirect effect of job stress on turnover intention $(\beta=0.14)$ is positive and significant. In addition, $36 \%$ of the variance in turnover intention, $6 \%$ of the variance in job stress and $47 \%$ of variance in job satisfaction are explained by the model.

Table (3) displays the fitness of the model through path analysis.

Table 3: Characteristics of the model fit through path analysis

\begin{tabular}{|c|c|c|c|c|c|}
\hline NFI & CFI & AGFI & $\begin{array}{c}\text { NFI } \\
\text { RFI }\end{array}$ & RMSEA & $\mathrm{df} /^{2} \mathrm{c}$ \\
\hline 0.95 & 0.98 & 0.94 & 0.97 & 0.064 & 1.83 \\
\hline
\end{tabular}

According to Table (3), the degrees of freedom to chi-square ratio $(\mathrm{df} / \mathrm{c} 2=1.83)$ goodness of fit $(\mathrm{GFI}=0.97)$, previously adjusted goodness of fit (AGFI=0.94)and root mean square error of approximation (RMSEA $=0.064$ ) are at an appropriate level. Therefore, the model fit can predict turnover intention among school counselors at the appropriate level.

\section{Discussion and conclusions}

This study aimed to investigate the relationship between resiliency and turnover intention with an emphasis on the mediating role of job satisfaction and job stress through path analysis. The path analysis results showed that the proposed model is fitted with the data, 
explaining $36 \%$ of the variance in turnover intention, $6 \%$ of the variance in job stress and $47 \%$ of the variance in job satisfaction.

The results are discussed according to research hypotheses:

According to the first hypothesis, resiliency has a direct effect on job satisfaction. Individuals who have high resiliency tend to show better health, higher self-esteem (Bookner, Mezakappa, Beardsley, 2003). Resilient individuals encounter potentially stressful factors, tend to have lower stress and reduce the risk of depression. Resiliency can challenge hard work and boring and tedious complexity of administrative work conditions, to enhance control over work and create job satisfaction and increase employee efficiency and productivity.

According to the second hypothesis, resiliency has a negatively direct effect on job stress. This finding was consistent with those of Edward (2005); Varlo and Edward (2007) and Lazarus (2004). Based on these findings, we can argue that counselors who deal with job problems with resiliency tend to show lower job stress. That is because resilience gives people the ability to face problems and tribulations of life and career without emotional injury, and even use the situations as an opportunity to grow and promote their personality. On the other hand, resilient individuals approach problems in creative and flexible ways, plan to solve issues and even hesitate to ask for help from others, and have complete resources for encountering problems.

According to the third hypothesis, job satisfaction has a direct effect on turnover intention. This finding was consistent with those of Huang et al. (2016) and Kuo et al. (2014). In explaining the results of the study, according to background research, job satisfaction is basically an effective factor in the employee behavior, which is why managers consider it important. There is an inverse relationship between job satisfaction and absenteeism and employee substitution, i.e. when job satisfaction is higher, substitution and subsequently absenteeism will be low. In most models of turnover, job satisfaction along with commitment is identified as the major force of turnover intention (Nadiri, Tanva, 2010, Center, Martin, 2007; Reilly, 2006)According to Porter and Steers (1973), turnover intention is mainly dominated by two factors: emotional responses to job and non-job variables. Many models of turnover intention assume that emotional reactions to the job are more important than the subsequent behavioral intentions. Two reasons can lead to employee dissatisfaction and turnover intention: encouragement to explore career options more attractive and individual feeling about what the future will reward for a job (D Kunick, Stilwell, 2004). In fact, unsatisfied people look for more attractive and better jobs. And secondly, the extent to which dissatisfaction will be there affect the turnover intention.

According to the fourth research hypothesis, job stress has a direct effect on turnover. This finding was consistent with those of Gochait et al. (2016) and Yang et al. (2016). Based on the results of the study, it can be argued when job stress intensifies, individuals begin to encounter the stressful situation in different ways. In fact, individuals face lower capability and energy for optimum performance whether consciously or unconsciously at the time of increased stress. If they continue to face stressful factors, there will be weakening 
performance. Hence, individuals tend to evade the stressful situations after degradation of performance.

According to the fifth hypothesis, occupational stress has a negative effect on job satisfaction. These findings were consistent with those of $\mathrm{Wu}$ and Norman (2006) and Jadkins and Keynes (2005) and Lavasani et al. (2008). According to the finding, it can be stated that increased stress in counselors led to lower job satisfaction. Pavlick and Ki Yen Len (2007) suggested that stress can disrupt the individual action in the psychological, social, physical and family realms, leading to job dissatisfaction, job errors and lower efficiency at work (quoted by and Asgari Neklzaeh, 2010). Hence, severe stress can lead to dire consequences in the counseling profession and undermine the morale of counselors in their ability to transfer that passion to their jobs. The counselors may reduce stress after a long time and get discouraged. In addition, the severe stress may reduce the quality of interaction with clients.

In addition, the sixth hypothesis results showed resiliency had a significant indirect effect on turnover intention. Therefore, job satisfaction and job stress mediate the relationship between resiliency and turnover intention. It can be concluded that resiliency leads to lower turnover in the counselors through increased job satisfaction and decreased job stress.

The findings of the present study have practical implications. Planning and implementation of any program to reduce turnover requires to identify the contributing factors. The results of this study could be of interest to planning, measures and reforms in organizations. In the present study, data were collected through self-report tools. Self-reported data are obtained using tools inadvertently or deliberately biased. We suggest that future studies adopt qualitative and hybrid techniques.

\section{References}

1. Randall, Ross; Altmayer, Elizabeth M. (2006). Job Stress. Translated by Gholamrezapour. Tehran: Baztab Publications. First Edition

2. Zabetian, R. (2011). The relationship between job stress and job satisfaction and working life quality of referees in the Premier League, master thesis, University of Tehran.

3. Asgari, Parviz; Nekolzadeh, Maryam (2010). The relationship between job stress and social support and job satisfaction among employees of National Drilling Company. New findings in Psychology, 5 (14), 37-52.

4. Lavassani G, M; Keyvanzadeh, M.; Arjomand, N. (2008). Spirituality of job stress, organizational commitment, and job satisfaction among nurses in Tehran. Contemporary Psychology, 3 (2), 61-73.

5. Hooman, Hiedar Ali (2008). Structural equation modeling using LISREL. Tehran: SEMAT.

6. Ahn, T. (2015). Locus of Control and Job Turnover. Economic Inquiry, 53(2), 1350-1365.

7. Allen, D. \& Bryant, Ph (2012). Managing Employee Turnover: Dispelling Myths and Fostering Evidence-Based Retention Strategies. Business Expert Press (September 3, 2012) 
8. Bougheas, S., Davidson, C., Upward, R., \& Wright, P. (2015). Structural adjustment, job turnover and career progression (No. 14). Action IS1104" The EU in the new complex geography of economic systems: models, tools and policy evaluation".

9. Buckner, J. C., Mezzacappa, E., \&Beardslee, W. R. (2003). Characteristics of resilient youths living in poverty: The role of self-regulatory processes. Development and psychopathology, 15(01), 139-162.

10. Charney, D. S. (2014). Psychobiological mechanisms of resilience and vulnerability.

11. Connor, K. M., \& Davidson, J. R. (2003). Development of a new resilience scale: The Connor-Davidson resilience scale (CD-RISC). Depression and anxiety, 18(2), 7682.Canrinus, E. T., Helms-Lorenz, M., Beijaard, D., Buitink, J., \&Hofman, A. 2012. Selfefficacy, job satisfaction, motivation and commitment: exploring the relationships between indicators of teachers' professional identity. European journal of psychology of education, 27(1), 115-132.

12. De Coninck, J. B., \& Stilwell, C. D. (2004). Incorporating organizational justice, role states, pay satisfaction and supervisor satisfaction in a model of turnover intentions. Journal of Business Research, 57(3), 225-231.

13. Edward, K. (2005). The phenomenon of resilience in crisis care mental health clinicians. International Journal of Mental Health Nursing, 14 (2): 142-148.

14. Fergus, S., \& Zimmerman, M. A. (2005). Adolescent resilience: A framework for understanding healthy development in the face of risk. Annu. Rev. Public Health, 26, 399419.

15. Garmezy, N. (1991). Children in poverty: Resilience despite risk. Psychiatry,56(1), 127-130.

16. Guchait, P., Paşamehmetoğlu, A., \& Madera, J. (2016). Error management culture: impact on cohesion, stress, and turnover intentions. The Service Industries Journal, 36(3-4), 124141.

17. Guchait, P., Paşamehmetoğlu, A., \& Madera, J. (2016). Error management culture: impact on cohesion, stress, and turnover intentions. The Service Industries Journal, 36(3-4), 124141.

18. Handlon, R.S. (2009). The departure of the insurance agent: The impact organizational commitment. organizational justice. and job satisfaction have on intent to leave in the insurance industry, August.

19. Hetherington, E. M., \& Blechman, E. A. (2014). Stress, coping, and resiliency in children and families. Psychology Press.

20. Holling, C. S., \& Gunderson, L. H. (2016). Resilience and adaptive cycles. In: Panarchy: Understanding Transformations in Human and Natural Systems, 25-62.

21. Hom PW., \& Griffeth RW. (1995). Structural equations modeling test of a turnover theory: cross-sectional and longitudinal analyses. J ApplPsychol;76:350-66 (June).

22. Huang, Y. H., Lee, J., McFadden, A. C., Murphy, L. A., Robertson, M. M., Cheung, J. H., \& Zohar, D. (2016). Beyond safety outcomes: An investigation of the impact of safety climate on job satisfaction, employee engagement and turnover using social exchange theory as the theoretical framework. Applied ergonomics, 55, 248-257.

23. Hudgins, T. A. (2016). Resilience, job satisfaction and anticipated turnover in nurse leaders. Journal of nursing management, 24(1), E62-E69.

24. Judkins, S., \& Rind, R. (2005). Hardiness, Job satisfaction, and stress among home health nurses. Home Health Care Management \&Practice, 17, 113-118. 
25. Kumpfer, K. L. (2002). Factors and processes contributing to resilience. In Resilience and development (pp. 179-224). Springer US.

26. Kuo, H. T., Lin, K. C., \& Li, I. C., (2014). The mediating effects of job satisfaction on turnover intention for long-term care nurses in Taiwan. Journal of nursing management, 22(2), 225-233.

27. Lazarus, A. (2004). Relationships among indicators of child and family resilience and adjustment following the September 11, 2001 tragedy. The Emory center for myth and ritual in American life. Available on: www.marila.emory.edu/faculty/Lazarus.htm.

28. Lee, Y., Lee, M., \& Bernstein, K. (2013). Effect of workplace bullying and job stress on turnover intention in hospital nurses. Journal of Korean Academy of Psychiatric and Mental Health Nursing, 22(2), 77-87.

29. Lu, H., Barriball, K. L., Zhang, X., While, A. E. (2012). Job satisfaction among hospital nurses revisited: A systematic review. International Journal of Nursing Studies, 49, 10171038 .

30. Luthar, S. S., Cicchetti, D., \& Becker, B. (2000). The construct of resilience: A critical evaluation and guidelines for future work. Child development, 71(3), 543-562.

31. Masten, A. S. (2001). Ordinary magic: Resilience processes in development. American psychologist, 56(3), 227.

32. Nadiri, H., \&Tanova, C. (2010). An investigation of the role of justice in turnover intentions, job satisfaction, and organizational citizenship behavior in hospitality industry. International journal of hospitality management, 29(1), 33-41.

33. Park, S. G., Min, K. B., Chang, S. J., Kim, H. C., \& Min, J. Y. (2009). Job stress and depressive symptoms among Korean employees: the effects of culture on work. International archives of occupational and environmental health, 82(3), 397-405.

34. Porter, L. W., \& Steers, R. M. (1973). Organizational, work, and personal factors in employee turnover and absenteeism. Psychological bulletin, 80(2), 151.

35. Rebollo-Sanz, Y. (2012). Unemployment insurance and job turnover in Spain. Labour Economics, 19(3), 403-426.

36. Riley, D. (2006). Turnover intentions: The mediation effects of job satisfaction, affective commitment and continuance commitment.

37. Rondeau, K. V., \&Wagar, T. H. (2016). Human resource management practices and nursing turnover. Journal of Nursing Education and Practice, 6(10), p101.

38. Rutter, M. (1999). Resilience concepts and findings: implications for family therapy. Journal of family therapy, 21(2), 119-144.

39. Rutter, M. (2012). Resilience: Causal pathways and social ecology. In The social ecology of resilience (pp. 33-42). Springer New York.

40. Senter, J. L., \& Martin, J. E. (2007). Factors affecting the turnover of different groups of part-time workers. Journal of Vocational Behavior, 71(1), 45-68.

41. Tsouloupas, C. N., Carson, R. L., Matthews, R., Grawitch, M. J., \& Barber, L. K. (2010). Exploring the association between teachers' perceived student mis behavior and emotional exhaustion: The importance of teacher efficacy beliefs and emotion regulation. Educational Psychology, 30(2), 173-189.

42. Warelow, P., \& Edward, K. (2007). Caring as a resilient practice in mental health nursing. International Journal of Mental Health Nursing, 16 (2): 132-135. 
Bulletin de la Société Royale des Sciences de Liège, Vol. 86, special issue, 2017, p. 189 - 200

43. Wu, L., \& Norman, I. J. (2006). An investigation of job satisfaction, organizational commitment and role conflict and ambiguity in a sample of Chinese undergraduate nursing students. Nurse Education Today, 26, 304-314.

44. Yang, H. C., Ju, Y. H., \& Lee, Y. C., (2016). Effects of job stress on self-esteem, job satisfaction, and turnover intention. Journal of Transnational Management, 21(1), 29-39.

45. Yang, H. C., Ju, Y. H., \& Lee, Y. C., (2016). Effects of job stress on self-esteem, job satisfaction, and turnover intention. Journal of Transnational Management, 21(1), 29-39. 